\title{
The Heartland Conservation Process: enhancing biodiversity conservation and livelihoods through landscape-scale conservation planning in Africa
}

\author{
Adam Henson, David Williams, Jef Dupain, Helen Gichohi and \\ PHILIP MURUTH I
}

\begin{abstract}
The African Wildlife Foundation (AWF) has developed and applied a landscape-scale conservation planning methodology in eight priority conservation landscapes in Africa, areas we call African Heartlands. The foundation of the African Heartland Program is a landscape-scale planning process that has been developed and applied as part of the overall Heartland Conservation Process. This process helps AWF and its partners develop intervention strategies that address critical threats to the ecological viability of these landscapes, and to specific biodiversity conservation targets, whilst also working to improve the livelihoods of local people. In applying this participatory planning process to eight conservation landscapes in Africa we have begun to document and learn about the benefits and limitations of planning and implementation at the landscapescale with stakeholders. We draw out lessons on the challenges and successes from our experience. Central to this are the merits of balancing a systematic science-based and pragmatic approach to landscape-scale conservation planning while addressing the needs and aspirations of local people. This approach could be particularly useful for other large-scale conservation planning efforts in developing countries where conservation objectives and human livelihoods are inextricably linked.
\end{abstract}

Keywords Africa, African Wildlife Foundation, biodiversity, conservation planning, landscape, livelihoods

\section{Introduction}

\footnotetext{
$\Lambda s$ the theory and practice of large-scale biodiversity conservation has evolved so has the development and use of landscape-scale planning tools and approaches. Methods such as systematic conservation assessment have been developed to prioritize areas for conservation action (Knight et al., 2006b). However, tools that stop short of

Adam Henson (Corresponding author) and David Williams African Wildlife Foundation, 1400 16th St., NW \#120, Washington, DC 20036, USA. E-mail ahenson@awf.org

JeF DupaIn African Wildlife Foundation, Kinshasa/Gombe, Republique Democratique Du Congo.

Helen Gichohi and Philip Muruthi African Wildlife Foundation, Nairobi, Kenya.

Received 23 June 2008. Revision requested 16 August 2008.

Accepted 4 November 2008.
}

translating information gained through systematic assessment into conservation action have led to an implementation crisis in conservation planning (Knight et al., 2006a). In seeking to address this gap the African Wildlife Foundation (AWF) has developed an applied planning process that results in tangible conservation interventions in Africa. AWF has been working in biodiversity conservation exclusively in Africa for $>45$ years to ensure the survival of some of the continent's most valued species and habitats. In 1999 AWF established its African Heartland Program, a landscape-level approach to conservation that includes both conservation and nature-based livelihood improvement goals.

The Program aims to conserve Africa's biodiversity in large conservation landscapes that have the scope to maintain wild species and conserve ecological processes in perpetuity. These large areas are often a mosaic of land units under individual, communal and state protection. As demonstrated by increased species extinction rates in small isolated reserves (Dobson, 1996; Woodroffe \& Ginsberg, 1998) protected areas may not, by themselves, conserve a high level of biodiversity. The Heartland Program therefore augments protected areas and helps to manage the surrounding areas, considering the needs of native species, ecosystem processes and local stakeholders. Such landscapes have the potential to provide economic benefits and ecosystem services that strengthen livelihoods of local people.

AWF has designed a suite of intervention strategies and applies them in different ways and intensities across the various Heartlands. These strategies are informed by an iterative planning process that includes systematic conservation assessment along with a compilation of existing information gathered from the experience of AWF and its partners. Strategies employed in Heartlands include: protection of critical habitats and corridors by bringing land under conservation management, development of conservation-based enterprises, applied research and species conservation, development of capacity and leadership for conservation and, where necessary, engagement in policy and legislation work with partner governments (Muruthi, 2004). The interventions are designed to halt or reverse the process of landscape fragmentation.

The foundation of the Heartland Program is a landscape-scale planning process that has been developed and applied as part of AWF's Heartland Conservation Process 
(AWF, 2003). This process includes all phases of an adaptive management project cycle. Here, however, we focus on the planning component. Specifically, we describe the spatially explicit decision process for determining the extent of landscapes using conservation targets and their habitats as planning units, and how that information leads to implementation of conservation strategies. Case studies from two Heartlands, Kilimanjaro and Congo, illustrate how the planning process provides a framework for the Heartland Conservation Process and contributes to AWF's goal of delivering conservation impact to priority landscapes in Africa.

AWF's landscape-level planning process is an iterative process of participatory planning with stakeholders, designed to develop a shared vision and plan of action for a landscape. Beginning in 1999 AWF's planning process has been developed in part through collaboration with The Nature Conservancy, with some key elements borrowed from their Conservation Action Planning methodology and adapted for use in Africa.

The main components in this landscape-scale planning process are: (1) identify biodiversity conservation targets, (2) conduct a socio-economic analysis of the landscape, (3) identify critical threats to conservation targets, (4) design threat reduction strategies while taking full advantage of opportunities available to strengthen livelihoods of local people, (5) apply conservation zoning that prioritizes interventions geographically and temporally, (6) compile these planning results into a 10-year strategic plan for the Heartland that are then divided into 3 -year and annual implementation plans, (7) systematically measure performance towards achievement of conservation goals and livelihood impacts for local people, and (8) utilize performance measures to inform adaptations to AWF's goals, strategy and interventions.

The basis for Heartland planning is to select features of biodiversity, i.e. conservation targets (Groves, 2003), which define a conservation landscape. Targets include individual species, species' assemblages, ecological communities and systems aiming to represent the suite of biodiversity of a site, with emphasis on threatened species. The conservation targets drive landscape-scale conservation planning, including the process of identifying threats, developing strategies, measuring impact and delineating the boundaries of a Heartland. We also consider socio-economic variables, emphasizing those influencing conservation feasibility (e.g. protected and administrative areas, population density, land uses and livelihood activities), depending on the local conditions and conservation objectives.

By working at the landscape scale AWF aims to conserve an area large enough to sustain a majority of conservation targets but that is a manageable size for intervention strategies to be applied effectively. AWF's initial planning and implementation horizon for work in a Heartland is $10-15$ years, thus accommodating temporal scales beyond usual project funding cycles. This enables the achievement of longterm conservation goals and also tracking of factors acting at larger spatial scales that may take longer to become apparent. The impacts of conservation strategies on the status of conservation targets and human livelihoods in Heartlands are monitored and measured, informing adaptive management and refinement of Heartland strategies.

AWF's planning tool and strategies continue to be refined based on the conservation needs in Heartlands, along with inputs from the wider conservation community. Heartland planning is generally undertaken through a variety of means, such as large participatory planning meetings, stakeholder consultations, and internal planning and analysis efforts. Significant engagement with key stakeholders in each landscape is undertaken throughout the planning process. Conservation stakeholders typically include: (1) government agencies (e.g. wildlife, national park, water, fisheries, forestry, environment, tourism, local government, social and economic services), (2) local communities and private landowners (customary leadership, resource users and women's groups), (3) private sector (tourism associations and operators, and other corporate partners), (4) nongovernmental organizations and donor agencies, and (5) conservation stakeholders, such as independent research teams and universities.

The Heartland Conservation Process has so far been applied to eight landscapes in 11 countries (Muruthi, 2004). These eight landscapes occur over a wide range of Africa's major habitats and often span two or more international boundaries. Methods used in this planning process are described here using two case studies that highlight common elements of planning used across the Heartlands, as well as detailing some unique planning tools and approaches from the programme in the Congo Basin.

\section{Kilimanjaro Heartland}

The Kilimanjaro Heartland, a 23,000 $\mathrm{km}^{2}$ transboundary landscape that straddles the border between southern Kenya and northern Tanzania, comprises the semi-arid savannah of the greater Amboseli ecosystem just north and west of Africa's highest peak, Mt Kilimanjaro, a World Heritage Site. This landscape is characterized by a wide range of physical and climatic features that give rise to a diverse range of habitats including Afro-montane, woodland, open savannah and freshwater. From Mt Kilimanjaro and Mt Meru the landscape rolls to low-lying areas of semiarid savannah in both Kenya and Tanzania. Mt Kilimanjaro's forests discharge much of their annual rainfall to the plains below through underground aquifers that feed the many springs and swamps in the Amboseli basin. In Kenya the Heartland's most distinguishing features include Amboseli National Park and seven large Maasai group ranches 
characterized by acacia-savannah grasslands. In Tanzania distinguishing features include Mt Kilimanjaro and Arusha National Parks, and the low-lying savannahs of Longido extending to Lake Natron in the Rift Valley. The Heartland contains great biological richness, with the wide-ranging elephant Loxodonta africana a keystone species. There are also large populations of ungulates, threatened species such as the black rhinoceros Diceros bicornis and wild dog Lycaon pictus, large carnivores, and a great variety of birds. Lake Natron, a designated Ramsar site currently without any protection status, provides critical breeding habitat for many birds, including lesser flamingos Phoeniconaias minor (Muruthi \& Frohardt, 2001).

The Heartland is predominantly inhabited by Maasai pastoralists. The dependence of pastoralism on space for livestock mobility and tracking of seasonal dispersed resources has allowed wildlife to thrive. However, Maasai culture is dynamic and many households are increasingly adopting cultivation on the edges of swamps and on mountain slopes. The influx of non-Maasai in the last 3 decades has further increased the area under cultivation (Campbell et al., 2003). In Kenya group ranches, a dominant land tenure system, are under threat because government policy is leading to increased subdivision into individually owned parcels. Together, the trends of increasing cultivation and subdivision are reducing the available open space and threatening the connectivity required to sustain both pastoralists and wide-ranging wildlife.

AWF has been working in the Kilimanjaro Heartland for $>30$ years. From an early long-term elephant research project in and around Amboseli National Park we have developed the landscape-scale approach described here. The primary determinants of the spatial extent of the landscape are the ranging patterns, key habitat areas, and movement corridors of elephants. By using elephants as the proxy indicator of the conservation landscape extent we were able to plan strategies with stakeholders that would address threats to elephants and other conservation targets. Additional determinants of the Heartland boundary were habitat requirements for priority species such as ungulates, black rhinoceros and large carnivores. Critical areas for freshwater biodiversity, such as Lake Natron, were also included, along with protected areas.

\section{Conservation targets and goals}

Identifying conservation targets and goals was initiated in 2000 by convening a panel of experts to assess the size, condition and landscape context of potential target species and ecological systems. These were then ranked for viability, which allowed us to gauge the overall biodiversity health of the landscape. The next step was to set conservation goals and refine the ecological boundaries of the Heartland based on the key target species, elephant. The full suite of conservation targets and goals for Kilimanjaro, from a participatory stakeholder planning process that began in 2000, are given in Table 1.

\section{Critical threats and conservation interventions}

Results from an analysis of threats and opportunities identified those threats that collectively are the most critical to biodiversity conservation targets, in this case conversion of land to agriculture, land subdivision, human-wildlife conflict and poaching. We used maps juxtaposing threats and conservation target areas (Fig. 1) to help identify opportunities for conservation interventions. Primary conservation strategies being implemented are strengthening protected areas, developing conservation-based enterprises with local people that leverage land for conservation, monitoring and protecting threatened species, supporting transboundary resource management processes and practices, and policy related tools that leverage land for conservation initiatives.

\section{Conservation zoning}

Conservation zoning builds on the analyses of conservation targets and goals, and threats and potential interventions. This generates a conceptual zoning map to identify intervention strategies for each zone in relation to conservation targets and threats. The conceptual zones chart the temporal and spatial direction of the programme over 10 years. Typically three major land-use zones are conceptually identified: (1) Core Areas such as national parks and other protected areas that are usually under some form of conservation management, (2) community and private lands in which AWF works closely with local people, private individuals or institutions to leverage conservation through a range of strategies that also target improving livelihoods, and (3) Special Habitat Areas that include critical wildlife habitats and corridors or other important ecological features of the landscape that require specific conservation strategies. Fig. 2 presents the zoning results, with current priority interventions. Conservation zoning has helped focus interventions in each land-use zone and provides a framework to bring priority land units under conservation management systematically over an extended period.

\section{Heartland Strategic Plan}

The culmination of the planning process is the development of a 10-year Heartland Strategic Plan that synthesizes results from conservation targets and goal setting, threats and opportunity analyses and conservation zoning. Components include a 3-year action plan and an annual implementation plan that forms the basis for budgeting and operational planning. 
TABLE 1 Conservation targets, goals, objectives and measures for the Kilimanjaro Heartland.

\begin{tabular}{|c|c|c|c|}
\hline Target & Goal & Objective & Measures \\
\hline \multicolumn{4}{|l|}{ Systems/ecological communities } \\
\hline $\begin{array}{l}\text { Acacia-grassland savannah } \\
\text { mosaic }\end{array}$ & $\begin{array}{l}\text { Maintain vegetative } \\
\text { composition \& condition; } \\
\text { restore degraded areas }\end{array}$ & $2-2.3 \mathrm{M} \mathrm{ha}$ & $\begin{array}{l}\text { Rate of change; } \% \text { of area } \\
\text { under conservation } \\
\text { management; condition }\end{array}$ \\
\hline $\begin{array}{l}\text { Wildlife migration routes/ } \\
\text { dispersal areas }\end{array}$ & $\begin{array}{l}\text { Maintain existing migration } \\
\text { corridors \& dispersal } \\
\text { areas, \& restore connectivity } \\
\text { between ecological core areas }\end{array}$ & $750-850 \mathrm{~K}$ ha & $\begin{array}{l}\text { Area of encroachment; level } \\
\text { of use }\end{array}$ \\
\hline $\begin{array}{l}\text { Hydrological systems: } \\
\text { wetlands, swamps, springs, } \\
\text { lakes, rivers, flood plains }\end{array}$ & $\begin{array}{l}\text { Restore dry-season flow } \\
\text { regimes \& water tables; } \\
\text { maintain species diversity } \\
\text { in wetlands; protect water } \\
\text { quality }\end{array}$ & $\begin{array}{l}36-39 \mathrm{~K} \text { ha (permanent } \\
\text { wetlands) }\end{array}$ & $\begin{array}{l}\text { Rate of change; \% of area } \\
\text { under conservation } \\
\text { management; no. of } \\
\text { adequately functioning } \\
\text { springs; condition }\end{array}$ \\
\hline $\begin{array}{l}\text { Montane forests: mist, cloud, } \\
\text { dry \& rainforests }\end{array}$ & $\begin{array}{l}\text { Restore former extent \& } \\
\text { condition/composition of } \\
\text { forests }\end{array}$ & $144-162 \mathrm{~K}$ ha & $\begin{array}{l}\text { Rate of change; } \% \text { of area } \\
\text { under conservation } \\
\text { management; condition }\end{array}$ \\
\hline \multicolumn{4}{|l|}{ Species' assemblages } \\
\hline $\begin{array}{l}\text { Large predators: lion } \\
\text { Panthera leo, leopard } \\
\text { Panthera pardus, cheetah } \\
\text { Acinonyx jubatus, striped } \\
\text { hyena Hyaena hyaena }\end{array}$ & $\begin{array}{l}\text { Increase population size of } \\
\text { declining predator } \\
\text { species \& safeguard range } \\
\text { of declining predators }\end{array}$ & $\begin{array}{l}500+\text { cheetah, lion, hyena, } \\
\text { leopard (research needed) }\end{array}$ & $\begin{array}{l}\text { Population size; } \\
\text { demographics; range extent }\end{array}$ \\
\hline $\begin{array}{l}\text { Declining ungulates: kudu } \\
\text { Tragelaphus imberbis, } \\
\text { giraffe Giraffa } \\
\text { camelopardalis, gerenuk } \\
\text { Litocranius walleri, eland } \\
\text { Taurotragus oryx, oryx } \\
\text { Oryx gazella }\end{array}$ & $\begin{array}{l}\text { Increase population size \& } \\
\text { restore range }\end{array}$ & Research needed & $\begin{array}{l}\text { Population size; } \\
\text { demographics; range extent }\end{array}$ \\
\hline \multicolumn{4}{|l|}{ Species } \\
\hline Elephant Loxodonta africana & $\begin{array}{l}\text { Maintain population \& secure } \\
\text { range }\end{array}$ & $2,000-2,500$ individuals & $\begin{array}{l}\text { Population size; } \\
\text { demographics; range extent }\end{array}$ \\
\hline Wild dog Lycaon pictus & $\begin{array}{l}\text { Increase population \& restore } \\
\text { secure predator-friendly } \\
\text { range }\end{array}$ & $500-600$ individuals & $\begin{array}{l}\text { Population size; } \\
\text { demographics; range extent }\end{array}$ \\
\hline $\begin{array}{l}\text { Black rhinoceros Diceros } \\
\text { bicornis }\end{array}$ & Restore population & Restock \& protect & $\begin{array}{l}\text { Population size; } \\
\text { demographics; range extent }\end{array}$ \\
\hline
\end{tabular}

\section{Performance and impact assessment}

To document strategy effectiveness and conservation impact systematically, a performance and impact assessment system was developed. Impact is measured in land and habitat protection, species conservation, reduction of threats, human livelihood measures such as economic returns from conservation enterprises, and capacity building and conservation leadership impacts.

Land and habitat protection This specifically tracks the size and conservation management status of land units and habitats that have been improved through AWF and partner interventions. We track areas now under varying levels of conservation management and sites where conservation activities are planned or underway that contribute to conservation goals. Another important measure tracked is the number and extent of wildlife movement corridors secured in a Heartland, which is critical for landscape integrity.

Species conservation Factors that we use to assess species viability depends on the species but generally information is gathered on the size of the population (for comparison to estimates of the historical population), reproductive rates, sex ratios, the minimum viable population, and the landscape context of species (the latter by evaluating connectivity and access to critical habitats, movement routes and dispersal areas). We use information from sources such as aerial surveys, wildlife censuses, in-house research and monitoring, data exchange with partners such as protected area authorities, and work with academic partners and individual scientists. We document the factors used to assess the viability of species targets and then provide a summary of the population trends. Because of the level of effort required and cost of measurement the viability of the 


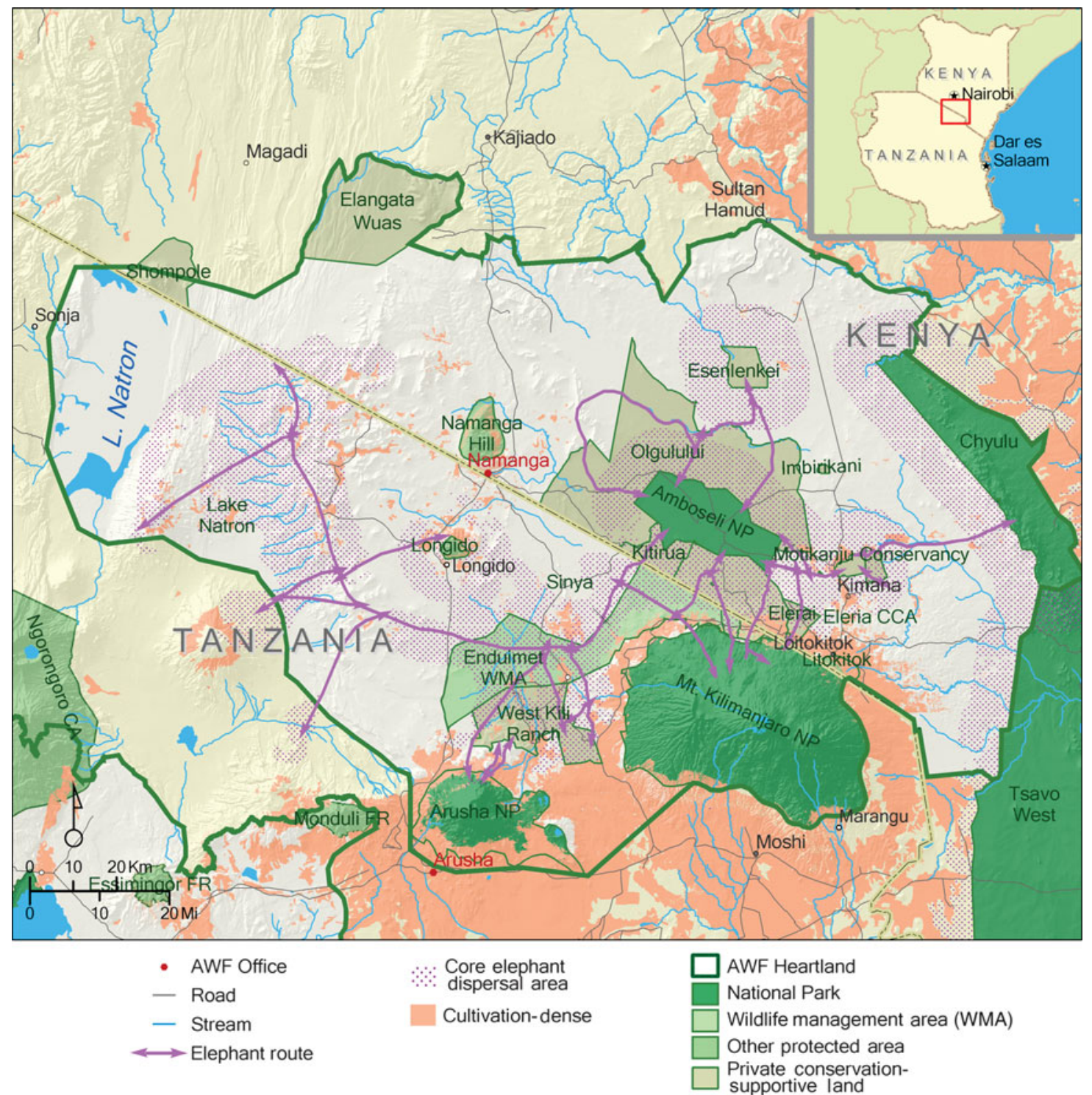

FIG. 1 Elephant dispersal areas, movement routes, and land uses in the Kilimanjaro Heartland. The inset shows the location of the main map on the Kenya-Tanzania border.

full suite of species' targets in a Heartland is undertaken every 5 years, and measured against baselines set in 2003. In addition, AWF and partners monitor the population trends of priority species' targets (often threatened or flagship species) at each site; these results are summarized on an annual basis.

Threat assessment Many conservation threats are monitored on an annual basis to help gauge the viability of species and the impact of related conservation interventions. Data from ranger-based monitoring programmes and community game scouts, along with information collected by Heartland staff, are used to report on these measures. We also monitor the effectiveness of land and habitat protection through analysis of land cover conversion. Landscape-level land conversion is assessed every 5 years, and specific highly threatened sites receive more scrutiny.
Results from this assessment are then used to adapt strategies to address the threats most seriously affecting conservation targets.

Human livelihoods We measure direct financial benefits disbursed to communities from conservation enterprises, including financial returns and jobs created. Gross revenue generated by enterprise projects are tracked annually, both tourism-based and non-tourism, along with the number of new enterprises opened for business each year. We are currently developing indicators that attempt to measure ecosystem services, linked to conservation interventions, for local people in Heartlands.

Capacity building and conservation leadership This measures the number of individuals who received AWF scholarships and formal training in conservation, and also tracks the number of institutions and partners whose 


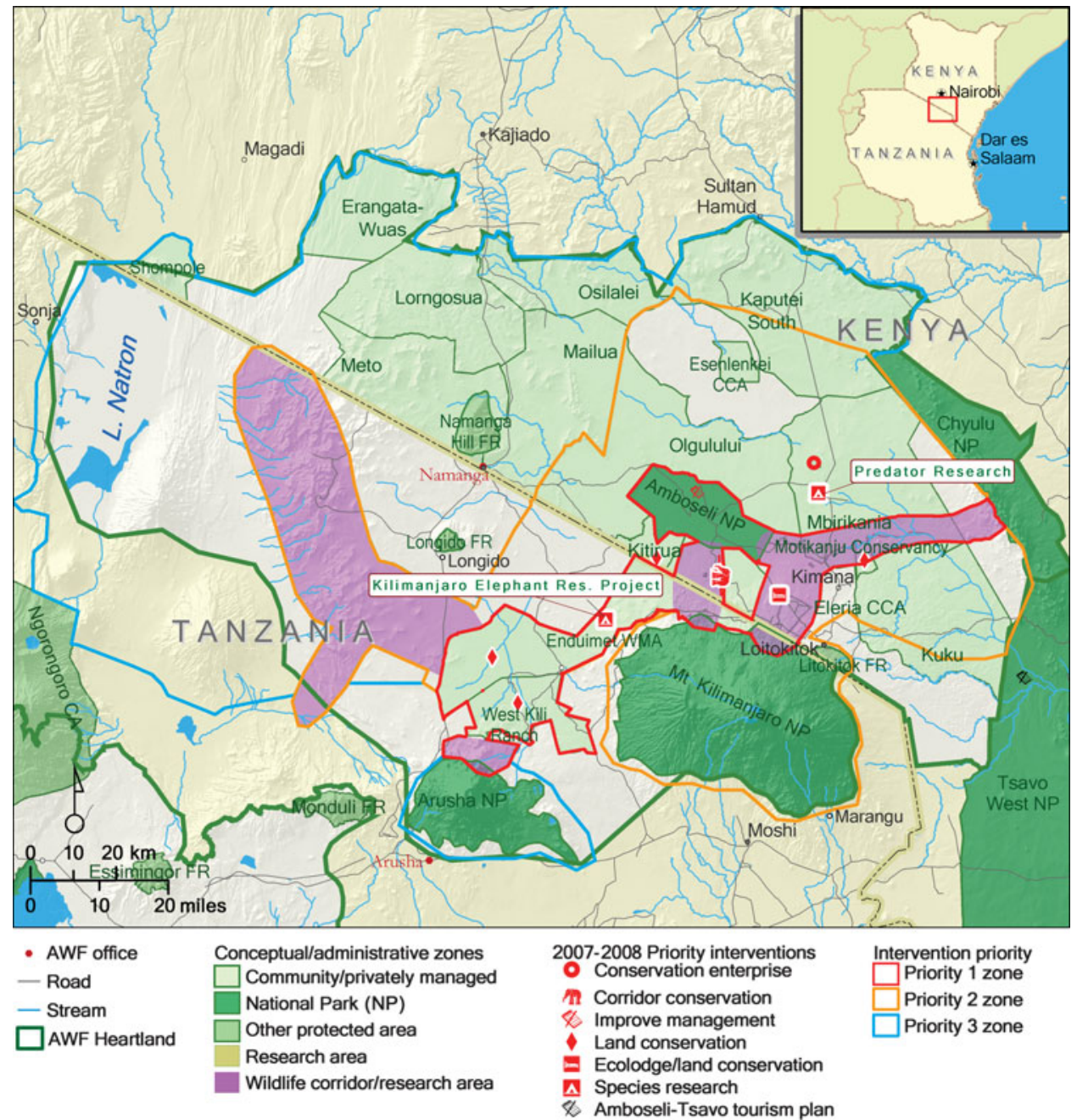

Fig. 2 Conceptual and administrative zones, and priority interventions in the Kilimanjaro Heartland. The inset shows the location of the main map on the Kenya-Tanzania border.

capacity was built to support implementation of conservation actions.

\section{Elephants}

Elephant conservation in the Kilimanjaro Heartland is led by the Kilimanjaro Elephant Conservation Project, working with partners such as the Amboseli Elephant Research Project. The Elephant Conservation Project focuses on the west Kilimanjaro region of Tanzania, monitoring population sizes, distribution and movement patterns, demography, and threats such as poaching and encroachment on corridors. Since baseline information was collected on the entire transboundary population in 2000 , the region's elephant population has nearly doubled to $2,000(1,400$ in Kenya and 600 in Tanzania). With threats from poaching reduced, AWF is investing in securing elephant habitat under conservation management. Research on elephant distribution and corridors has informed and strengthened the conservation rationale behind AWF's interventions.
Monitoring of elephants using global positioning system radio-collar data bolstered and shaped the vision of a series of conservation areas linking Amboseli and Arusha National Parks. In designing a landscape conservation approach for the Heartland elephants were used as the primary conservation target to determine the spatial extent of the landscape. The range and movement patterns of elephants were proxy indicators for important biodiversity areas and helped inform our landscape-scale strategy. Since 2002 AWF and partners have worked with local communities and government authorities to leverage over 100,000 ha of additional land under conservation management, involving nine community-conservation areas and a new Wildlife Management Area, Enduimet.

\section{Congo Heartland}

The Congo Heartland, also known as the Maringa/LoporiWamba forest landscape, encompasses $74,000 \mathrm{~km}^{2}$ of lowland rain and swamp forest in Equateur Province in 
north-central Democratic Republic of Congo (DRC). The ecological value of the Heartland is high and globally significant as this area is a representative subsection of the larger Guinean-Congolian lowland rainforest ecoregion. This landscape is biodiverse, with threatened species that include the bonobo Pan paniscus, forest elephant Loxodonta africana cyclotis, Congo peacock Afropavo congensis and other rare primates, amphibians and reptiles. The landscape also contains diverse avifauna and abundant fisheries. The landscape has two protected areas: the $3,625 \mathrm{~km}^{2}$ LomakoYokokala Faunal Reserve, which was officially gazetted in 2006, and the $481 \mathrm{~km}^{2}$ Luo Scientific Reserve. Many opportunities have been identified for introducing other types of protected areas, including community-managed forest reserves and concessions.

The region was severely affected by the Second Congo War (1998-2003) and remains one of the Congo Basin's least developed and most remote areas. Its 700,000 inhabitants are some of the poorest in Africa; most depend on natural resources to meet basic needs. The remoteness means the inhabitants have been denied many of the benefits of new democratization and economic development initiatives. The landscape's underdevelopment, however, has also left it largely intact: only $8 \%$ of the area is dominated by people. Being heavily dependent on natural resources, many communities have a strong desire to be included as partners in the development of improved natural resource management.

Landscape planning for this Heartland followed the Heartland Conservation Process. Unlike AWF's investment in the Kilimanjaro Heartland, where we had worked for $>20$ years before adopting the landscape conservation approach, our entry into this landscape coincided with the launch of USAID's Central Africa Regional Program for the Environment (CARPE) support for forest and biodiversity conservation in 11 central African landscapes. AWF first engaged here in 2003, with no previous experience in this part of DRC. Initiating a new conservation and development programme in this landscape provided opportunities for AWF to apply lessons learnt from previous Heartland planning and implementation in East and Southern Africa. Another relevant factor when looking at the Congo Heartland as a case study is the particular emphasis that USAID-CARPE has placed on developing landscape/landuse plans for CARPE-supported landscapes. AWF, as leader of the Maringa/Lopori-Wamba landscape consortium, has worked closely with the government of DRC to develop and test landscape planning and zoning in this forest landscape, to be used as a model for a land-use planning methodology across the Congo Basin forests of DRC. AWF established a technical team that included partners such as the US Forest Service, University of Maryland, Université Catholique de Louvain and USAID-CARPE, thus resulting in a more robust planning process.
At the start of programme implementation AWF refined the spatial extent of the landscape by considering the results of biological and socio-economic field surveys, in tandem with previous regional prioritization efforts that identified this landscape as a high priority. AWF revised the landscape limits using the watershed boundaries of the Lopori and Maringa Rivers. As a relatively intact forest landscape dominated by these rivers, watersheds were seen as natural management units. Five years of reconnaissance and data collection have validated this adjustment in both ecological and management terms. For management purposes we also consider the four administrative territories in this landscape and related sub-units when planning interventions and stakeholder consultations.

The overall goal of the Congo Heartland, which also corresponds to USAID-CARPE's Strategic Objective for the Congo Basin, is to reduce the rate of forest degradation and loss of biodiversity through increased local and national resource management capacity in support of poverty alleviation strategies. Specific conservation targets that the Congo Heartland is working to conserve (Table 2) are those elements of biodiversity that have been prioritized for conservation action and form the basis for conservation planning.

\section{Critical threats and conservation interventions}

Critical threats to biodiversity in this landscape are deforestation for agricultural expansion and human settlements, and commercial bushmeat hunting and trade. Ultimate causes of these threats are inadequate agricultural policy, lack of market access and weak governance. The potential for resumption of industrial-scale logging is a threat because of weak governance in the forest sector. Conservation interventions by AWF and partners in this Heartland are based on participative land-use planning and zoning focused on establishing a network of protected areas, and Community-Based Natural Resource Management areas with improved livelihood strategies such as agro-pastoral, fisheries and forest management. A key

TABLE 2 Conservation targets for the Congo Heartland.

\begin{tabular}{l}
\hline Systems/ecological communities \\
\hline Forest (primary, secondary, swamp) \\
Hydrological systems: wetlands, swamps, rivers, \\
$\quad$ flood plains \& fisheries \\
Species' assemblages \\
Large mammals \\
Primates \\
Species \\
Bonobo Pan paniscus \\
Forest elephant Loxodonta africana cyclotis \\
Congo peacock Afropavo congensis \\
\hline
\end{tabular}


element of our landscape strategy is to minimize habitat destruction by containing areas for cultivation to zones designated for community use.

\section{Conservation zoning and land use planning}

The objective of conservation zoning and land use planning for the Congo Heartland is to consolidate the needs of the local human population and biodiversity, and incorporate these into a land-use plan that renders the landscape ecologically, economically and socially viable. Recognizing that the landscape is largely intact, and the need to accommodate a growing human population, AWF is emphasizing where to encourage human development while maintaining connectivity between core wilderness areas. The landscape's historical insecurity and isolation means that data are few, creating a challenge for the technical conservation planning team.

Contrary to other Congo Basin landscapes and Heartlands, AWF has resisted using a species-driven approach because data characterizing species conservation targets fall below minimum standards. We do, however, have good characterizations of threats and human uses of the landscape. Our conservation planning in the Congo Heartland focuses on the intersection of models of wildlife habitat suitability and projected human land requirements. It also considers population growth estimates to design an optimal conceptual zoning configuration balancing conservation and human needs.

Based on research on land use requirements and an estimated $3 \%$ population growth rate, the team predicts a $25 \%$ increase in the area used for cultivation or settlement by 2015 . To reconcile this anticipated increase in human demand for land with that required for conservation, the team used geographical information system (GIS) spatial models to generate landscape suitability models for the wildlife and human habitat, and evaluated the overlap in habitat suitability. With MARXAN (2009), conservation planning software for identifying suitable areas for a suite of species conservation targets, a model was generated to identify areas most suited for future human expansion while considering conservation-motivated constraints with respect to a wildlife suitability model. Factors driving the model's areas of human expansion included the influence of existing settled/cultivated areas, mobility and access to markets. Wildlife suitability used large, intact forest blocks, bonobo habitat, and connectivity between forest blocks as a proxy for a suite of species-specific models. The intersection of human habitat suitability and wildlife suitability models permit the identification of priority areas for potential conflict resolution and objective compatibility (Fig. 3). Adding largely qualitative considerations of socio-economic factors (e.g. community interests, status of forestry concessions), the overlap of wildlife and human habitat suitability models provide the foundation for the design of conceptual zones (Fig. 4).

Because of poor species information AWF is consulting panels of species experts, focusing on conservation target species such as bonobo, forest elephant and Congo peacock, to review conservation planning results for species and recommend intervention strategies. The technical team uses satellite imagery and spatial modelling to explore conservation planning scenarios and monitor land use and land cover trends (principally deforestation). We are investigating the ability of satellite-detected active fire points (Justice et al., 2002) to serve as proxy indicators of deforestation and habitat destruction. If successful these data will help predict habitat destruction patterns and help AWF assess the impact of conservation interventions on these patterns. Ultimately our objective is to restrict habitat destruction to areas designated for community use. As an extension to monitoring intervention impacts on habitat destruction, a methodology is currently being developed to monitor impacts on livelihoods.

\section{Discussion}

\section{Advantages}

There is widespread evidence that to address the implementation crisis affecting biodiversity conservation, planning must integrate systematic conservation assessment with an implementation strategy that takes results from systematic assessment and applies it to solve actual conservation problems (Knight et al., 2006a). The African Heartland planning process can help lead to a clearly articulated vision for a landscape, with objectives and desired outcomes identified along with an implementation plan for conservation action. Results from the planning process emphasize interventions that are focused at the landscape scale and avoid disparate low-priority activities that do not clearly achieve conservation objectives. The development of a Heartland strategic plan also facilitates coherent presentation to authorities, local communities and other stakeholders on the shared vision and objectives for a Heartland.

AWF's conservation target and goal-setting approach is science-based, pragmatic, flexible, incorporates the needs of local people as well as biodiversity, and can be applied in areas that are data rich or poor. The Heartland planning process can also provide a consistent framework for a variety of low-technology planning tools (e.g. stakeholder meetings) as well as high-technology tools such as GIS, spatial modelling, and decision support tools such as MARXAN. Continuous monitoring and data collection, including research where possible, helps generate information that informs refinements of the Heartland plan and intervention strategies. 


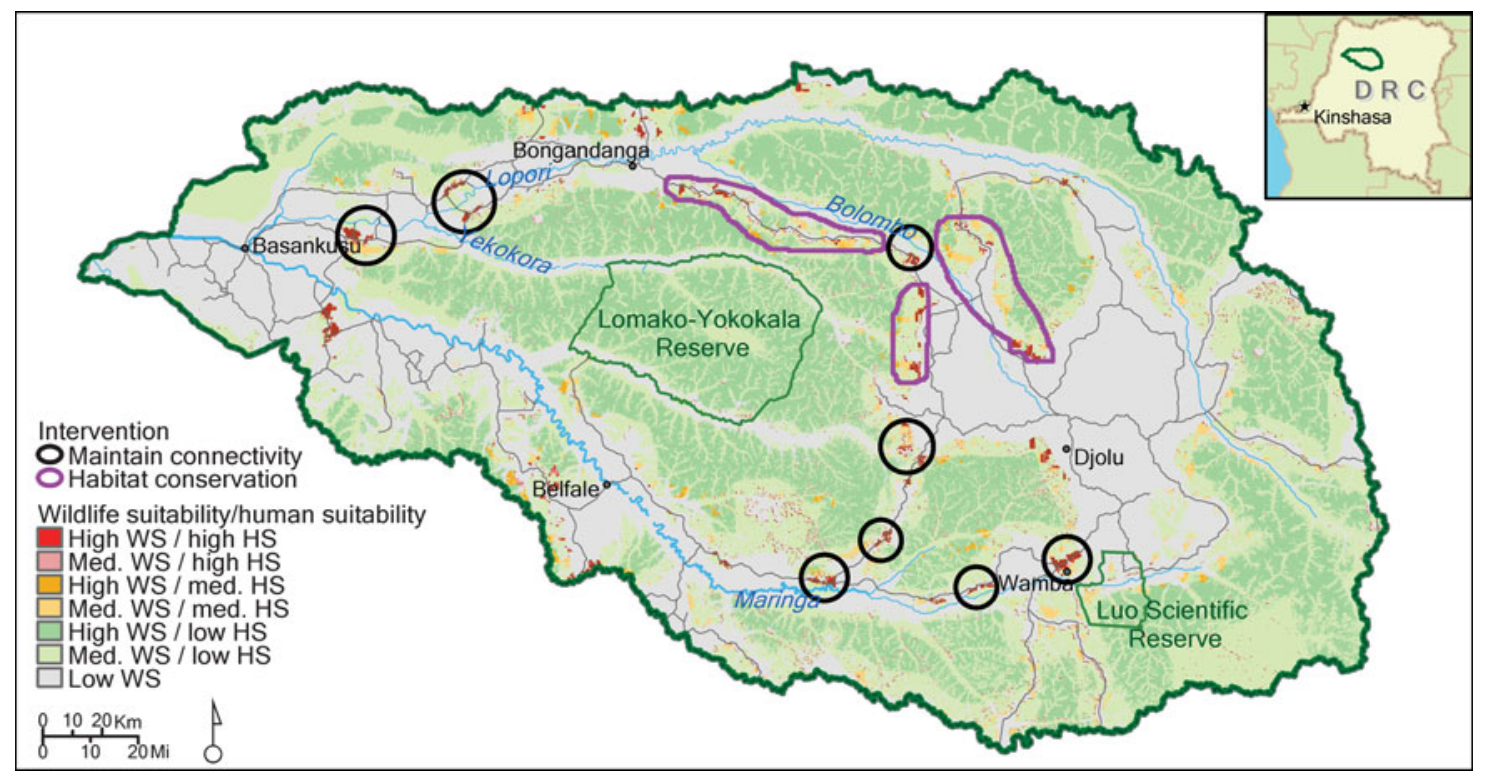

FIG. 3 Interventions and wildlife and human habitat suitability in the Congo Heartland. The inset shows the location of the main map in the Democratic Republic of Congo.

In Heartlands local people play a central role in determining conservation strategies, from target setting to implementation; this helps facilitate buy-in at each level of the participatory planning process. Opportunities for threat reduction that contribute to peoples' livelihoods, such as human-wildlife conflict mitigation, are emphasized, as opposed to seeing people primarily as threats to conservation. AWF commits to long-term presence in Heartlands, which leads to a more effective bottom-up approach.

\section{Challenges}

Execution of a landscape-scale conservation strategy is challenging. It requires weaving together many interventions and strategies to solve complex challenges that threaten species and their habitats, whilst simultaneously integrating human concerns and, in some cases, people's livelihoods. The interventions also need to be undertaken at a large scale and therefore significant financial and human resources are required for eventual success.

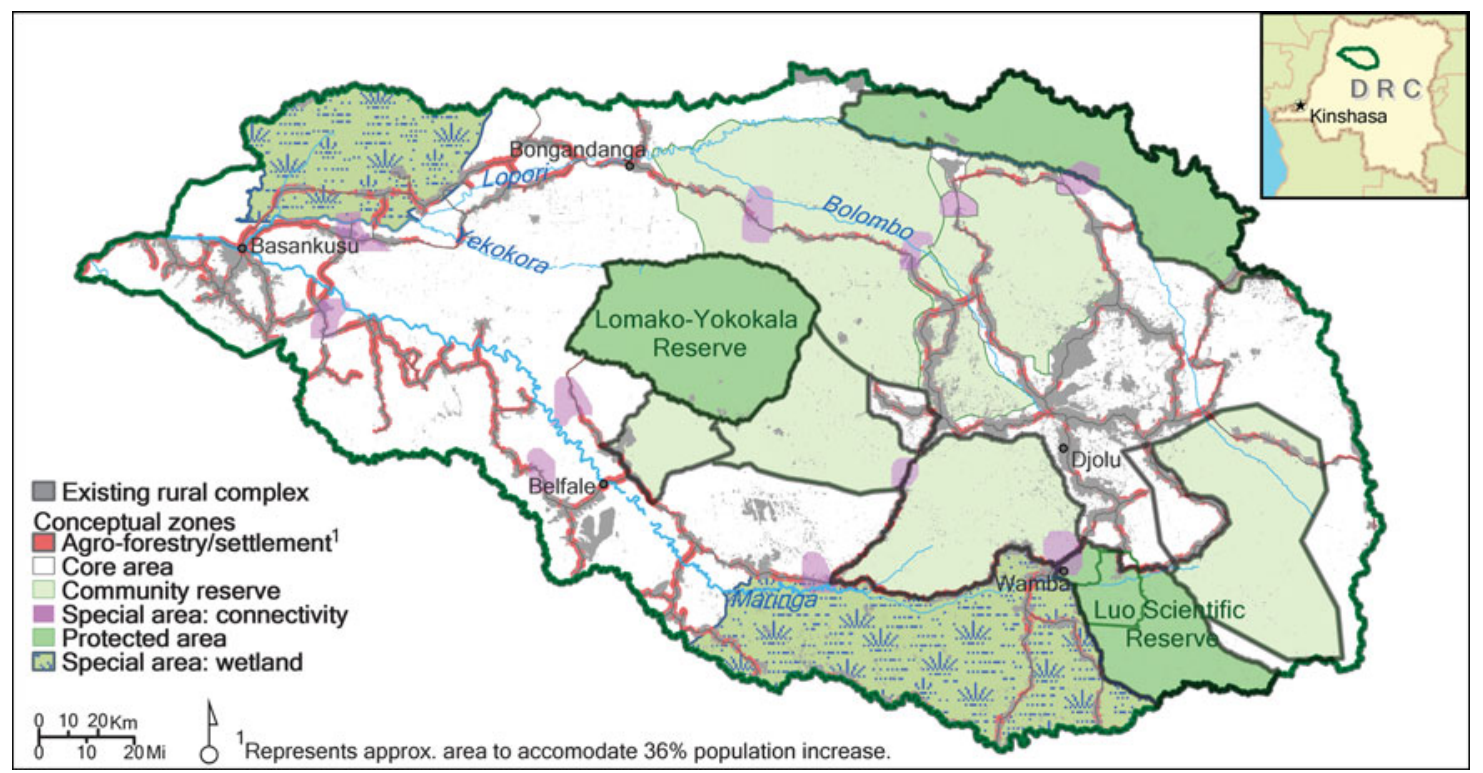

FIG. 4 Preliminary conceptual zoning in the Congo Heartland. The inset shows the location of the main map in the Democratic Republic of Congo. 
Another challenge is that a mechanism to gain formal recognition of landscape plans has been lacking in many areas where we work. Although the plans often gather inputs from local governments, national wildlife and resource conservation agencies, civil society and local people, they have not been adopted in any country as formal conservation plans for the areas in question. Landscape plans have been conceptual and can sometimes be preempted by seemingly more urgent priorities. This can lead to diversion from agreed conservation strategies despite agreements, in principle, with relevant stakeholders.

Data collection and sharing with partners before stakeholder meetings is desirable. We have found that if little information is presented in planning meetings stakeholders are much less open for collaboration and outcomes are less constructive. It pays to invest time and resources in collection of baseline data before initiating a public participatory planning process.

Lastly, a gap in AWF's approach is that charismatic mega-vertebrates frequently perform poorly as umbrella species for unrelated taxa (Caro et al., 2004). With this in mind AWF has in some landscapes placed too much emphasis on large mammals. This is especially true for landscapes where inclusion of less conspicuous species as conservation targets has not been possible because of a lack of information on a wider range of species.

\section{Successes and failures to inform future work}

AWF feels that the Heartland approach has been useful in identifying and prioritizing key habitat and landscape connectivity areas and then developing protection strategies. Conservation interventions have involved a variety of approaches, including ecological research, community engagement, conservation enterprise, institutional development, land purchase/easement and national level policy work, underscoring the value of a broad toolkit backed by a science-based planning process. An example of how this planning approach led to achievement of conservation objectives can be seen in the Kilimanjaro Heartland. AWF researchers warned that settlers were encroaching into the Kitenden corridor, a vital connection between the Amboseli plains and Mt Kilimanjaro, and AWF engaged local authorities and communities to demarcate and protect the corridor. Another example is the securing of Manyara Ranch, a critical land unit in the Kwakuchinja wildlife corridor in the Maasai Steppe Heartland in northern Tanzania, which entailed the formation of the Tanzania Land Conservation Trust and extensive community and government engagement. Both examples demonstrate how landscape-scale planning and implementation has delivered conservation results in priority landscapes. Such tangible conservation successes can then be used to demonstrate the merits of
AWF's conservation approach to leverage additional conservation investment.

In some areas, such as in the Congo Heartland, we have found that a public participation strategy is needed, as ownership of the landscape planning process by local people and government is important. In Congo for example, the planning team limited itself in early stages to widespread discussions of the concept of landscape planning and zoning, with a focus on the need to look at a broad scale. Thus, the planning team met with representatives of government and local communities. It was important that stakeholders understood that no decisions would be taken without widespread consultation and agreement.

Landscape planning is a complex task that requires a multitude of expertise. Such expertise should be represented in the landscape planning team but one is unlikely to find the complete set within a single organization. It is important to understand the need to build consortia of partners that can bring needed expertise to bear. Too often single, large organizations claim to have all the required expertise available in-house. AWF understands the need to create synergies between organizations that contribute complementary insights for comprehensive land-use planning. In addition, the selected partners often contribute different perspectives on how to approach landscape planning. Finally, because the diversity of expertise needed evolves during the landscape planning process, the composition of the planning teams should be dynamic.

\section{Implications}

Whereas identification of priority areas for conservation in early stages of the Heartland Program was informed largely by expert opinion in conjunction with stakeholder input, AWF is now adopting more systematic conservation assessment approaches. In the Congo Heartland we need to continue building on the spatial modelling to enable zoning that considers future conservation target and threat distributions and viability scenarios based on GIS datasets. The models should consider a broader range of taxa as well as the implications of climate change on habitat. These second generation spatial models will require more input and validation data. To source these we need to develop more systematic methodologies for landscape-level data collection (socio-economic and biophysical), which will also improve measurements of conservation impact.

Based on initial work in the Congo Heartland we believe that our use of spatial modelling and satellite data for simultaneously planning and monitoring for conservation impact may prove an efficient strategy that could be replicated elsewhere in the Congo Basin. To be meaningful these approaches must be combined with data collected in the landscape, and feedback mechanisms must be established as part of the public participation strategy to ensure data validation. 
For AWF the Congo Heartland has served as a laboratory to explore spatial modelling techniques to benefit conservation planning and results monitoring. Now the challenge is to adapt these tools developed in the Congo and apply them to other Heartlands. Further effort is required across our Heartlands in standardization and cross-site learning to turn an effective approach into a systematic tool that can be used across the Heartland Program. In East African Heartlands, for example, AWF has extensive experience and knowledge of engaging communities in participatory natural resources management that could contribute to and benefit similar work in other Heartlands.

\section{Summary}

AWF feels that landscape-scale planning has led to increased efficiency and use of scarce conservation resources where action is most needed. Before utilizing large-scale planning AWF's efforts were relatively uncoordinated and ineffective, with Heartland staff engaged in numerous disparate projects while often neglecting the most pressing conservation needs. The landscape planning and conceptual zoning process has brought multidisciplinary teams together that consider landscape-scale issues before identifying zones and subsequent priority interventions. At the same time, we are cognizant of the peril of overemphasizing conservation planning at the expense of implementation and results. AWF's long-term emphasis on applied field research and conservation, and recent emphasis on measuring staff performance in terms of individual contributions to successful conservation interventions, help counter a tendency for over-planning.

A main lesson that AWF has learnt is the need to plan conservation interventions using the best scientific information available, in a consistent planning framework, and the importance of taking these planning results and investing in on-the-ground interventions. Achieving transformational impact at the landscape scale has not yet been achieved in any of the Heartlands, although we have made significant progress towards this goal in some places.

\section{Acknowledgements}

AWF would like to acknowledge the many partners that it works with in Africa and beyond to achieve conservation objectives and development in Africa. This article highlights the work of many AWF colleagues over the years and specifically the Heartland teams implementing programmes in the Kilimanjaro and Congo Heartlands. Consortium partners implementing joint work in conservation planning in the Congo Heartland also include ICRAF-The World Agroforestry Centre, SNV, World Fish Centre, University of Maryland, Université Catholique de Louvain, and REFADD, a Congolese NGO working on gender issues. The Nature Conservancy has also been an important partner in developing and advancing AWF's conservation planning efforts in Africa. Annette Lanjouw played an instrumental role in the overall development of AWF's planning approach and helped with facilitation of Heartland planning meetings, and AWF is grateful for her contributions. The development of AWF's Heartland conservation approach was made possible by the generous support of the United States Agency for International Development's (USAID) Global Conservation Program (GCP), specifically through a Leader with Associates Cooperative Agreement Award LAG-A-00-99-00053. This article was made possible with additional USAID-GCP funding under Associate Cooperative Agreement Award EPP-A-00-03-00023. The contents are the responsibility of the authors and do not necessarily reflect the views of USAID or the United States government.

\section{References}

African Wildlife Foundation (2003) Heartland Conservation Process (HCP). Unpublished Report. AWF, Nairobi, Kenya.

Bennet, A.F. (2003) Linkages in the Landscape: The Role of Corridors and Connectivity in Wildlife Conservation. IUCN, Gland, Switzerland.

Campbell, D., Gichohi, H., Mwangi, A. \& Chege, L. (2000) Land use conflict in Kajiado District, Kenya. Land Use Policy, 17, $337-348$.

Caro, T.M., Englis, A., Fitzherbert, E. \& Gardner, T. (2004) Preliminary assessment of the flagship species concept at a small scale. Animal Conservation, 7, 63-70.

Didier, K.A., Glennon, M.J., Novaro, A., Sanderson, E.W., Strindberg, S., Walker, S. \& DiMartino, S. (2009) The Landscape Species Approach: spatially-explicit conservation planning applied in the Adirondack, USA, and San GuillermoLaguna Brava, Argentina, landscapes. Oryx, 43, 476-487.

Dobson, A.P. (1996) Conservation and Biodiversity. Freeman and Company, New York, USA.

Forman, R.T.T. (1998) Land Mosaics: The Ecology of Landscapes and Regions. Cambridge University Press, Cambridge, UK.

Groves, C.R. (2003) Drafting a Conservation Blueprint. A Practitioner's Guide to Planning for Biodiversity. Island Press, Washington, DC, USA.

Hоввs, R.J. (1993) Effects of landscape fragmentation on ecosystem processes in the Western Australian wheatbelt. Biological Conservation, 64, 193-201.

Justice, C.O., Giglio, L., Korontzi, S., Owens, J., Morisette, J.T., Roy, D. et al. (2002) The MODIS fire products. Remote Sensing of Environment, 83, 244-262.

Knight, A.T., Cowling, R.M. \& Campbell, B.M. (2006a) An operational model for implementing conservation action. Conservation Biology, 20, 408-419.

Knight, A.T., Driver, A., Cowling, R.M., Maze, K., Desmet, P.G., Lombard, A.T. et al. (2006b) Designing systematic conservation assessments that promote effective implementation: best practice from South Africa. Conservation Biology, 20, 739-750.

MARXAN (2009) http://www.uq.edu.au/marxan/ [accessed 1 August 2009].

Muruthi, P.M. (2004) African Heartlands: a science-based and pragmatic approach to landscape-scale conservation in Africa. In Terrestrial Ecoregions of Africa and Madagascar: A Conservation Assessment (eds N. Burgess, J. D’Amico Hales, 
E. Underwood \& E. Dinerstein), pp. 168-172. Island Press, Washington, DC, USA.

Muruthi, P.M. \& Froh ARDt, K. (2001) Beyond Boundaries: Transboundary Natural Resource Management in the Amboseli-LongidoKilimanjaro Area. Biodiversity Support Program, Washington, DC, USA. Http://www.worldwildlife.org/bsp/publications/africa/121/ 188/titlepageHTML.htm [accessed 20 April 2009].

Poinin, K., Richter, B., Anderson, M. \& Richter, H. (2000) Biodiversity at multiple scales: functional sites, landscapes, and networks. BioScience, 50, 133-146.

Redford, K.H., Coppolillo, P., Sanderson, E.E., Da Fonseca, G.A.B., Dinerstein, E., Groves, C. et al. (2003) Mapping the conservation landscape. Conservation Biology, 17, 116-131.

Wells, M.P. \& Shane, T.O. (2004) Integrating protected area management with local needs and aspirations. Ambio, 33, 513-519.

Woodroffe, R. \& Ginsber G, J.R. (1998) Edge effects and the extinction of populations inside protected areas. Science, 280, 2126-2128.

\section{Biographical sketches}

Adam Henson, Director of Conservation Planning at AWF, provides technical support to AWF's programme in conservation planning and performance monitoring. David Williams is Director of Conservation Geography where he oversees AWF's GIS, which is used for analysis and integration of spatial data to bolster AWF's landscapelevel conservation programmes. JeF DUPAIN is Director of AWF's conservation programme in the Democratic Republic of Congo. He carries out research on bonobo conservation and the bushmeat trade. As AWF's President, Helen Gichонi provides overall leadership and supervises the implementation of AWF's conservation programmes in Africa. Her research interests are in grassland ecology. Philip Muruthi is AWF's Senior Director of Conservation Science. His research interests are animal ecology, the impact of humans on wildlife populations, and conservation biology. He is also interested in the role of wildlife conservation in enhancing livelihoods of local people. 